\title{
Bacterial Meningitis of Infants and Children under Five Years Old in Brazzaville-Congo
}

\author{
E. Moyen ${ }^{1,2 *}$, S. S. J. Dinga Boudjoumba1, J. Kambourou ${ }^{1,2}$, A. P. G. Oko, A. R. Okoko ${ }^{1,2}$, G. Moyen ${ }^{1,2}$ \\ ${ }^{1}$ Faculty of Health Sciences, Marien Ngouabi University, Brazzaville, Congo \\ ${ }^{2}$ Pediatric Intensive Cares Unit, Brazzaville Teaching Hospital, Brazzaville, Congo \\ Email: *engoba_m@yahoo.fr
}

How to cite this paper: Moyen, E., Dinga Boudjoumba, S.S.J., Kambourou, J., Oko, A.P.G., Okoko, A.R. and Moyen, G. (2017) Bacterial Meningitis of Infants and Children under Five Years Old in Brazzaville-Congo. Open Journal of Pediatrics, 7, 300-308. https://doi.org/10.4236/ojped.2017.74035

Received: September 19, 2017

Accepted: December 2, 2017

Published: December 5, 2017

Copyright () 2017 by authors and Scientific Research Publishing Inc. This work is licensed under the Creative Commons Attribution International License (CC BY 4.0).

http://creativecommons.org/licenses/by/4.0/

\begin{abstract}
Objective: to determine the epidemiological characteristics and outcomes of bacterial meningitis of infants and the children in Brazzaville after the introduction of Haemophilus influenzae type $\mathrm{b}$ and Pneumococcal vaccines. Patients and Methods: files of children aged from 1 to 59 months, hospitalized for bacterial meningitis between January, 2004 and December, 2013 in the Paediatric Intensive Care Unit of the Teaching Hospital of Brazzaville were reviewed. Studied variables included: age, gender, place of residence, immunization status, motive of hospitalization, laboratory analysis of the cerebrospinal fluid, and the outcome. Results: Overall 219 cases were included out of 22,148 admitted children, thus a frequency of $0.99 \%$. Of the 219 children, $144(65.8 \%)$ did not receive any dose of the Haemophilus influenzae b vaccine, 15 (6.8\%) were incompletely vaccinated, and 60 (2.4\%) were up-to-date. Concerning the Pneumococcal vaccine, 213 (97.2\%) were not vaccinated, three (1.4\%) were incompletely vaccinated, and the other three (1.4\%) were up-to-date. Meningitis was severe in 139 cases (63.3\%). The main isolated germs were: the Streptococcus pneumoniae with 46 cases (41.0\%), and Haemophilus influenzaeb with 16 cases (14.3\%). Ninety-five children (43.4\%) died in the course of the disease. The mortality rate was $7.1 \%$ before the introduction of the Haemophilus influenzae b vaccine, and $9.9 \%$ after its introduction, $8.5 \%$ after the introduction of the Pneumococcal vaccine. The lethality was $37 \%$ before and $45.1 \%$ after the introduction of the Haemophilus influenzae b vaccine and $52.8 \%$ after the introduction of the Pneumococcal vaccine. Conclusions: The high frequency and mortality rate due to meningitis necessitates the strengthening of the Expanded Program on Immunization.
\end{abstract}

\section{Keywords}

Bacterial Meningitis, Children, Brazzaville-Congo 


\section{Introduction}

Bacterial meningitis is frequent and responsible for a considerable mortality [1] [2] [3]. According to the World Health Organization (WHO), 1.2 million people are considered to be suffering from bacterial meningitis per year in the world, among whom 135,000 deaths are reported [2] [4]. Several germs are involved and depend on the age groups, and parts of the world. Concerning infants and children, the main germs are Streptococcus pneumoniae, Haemophilus influenzae type $b$, and Neisseria meningitidis.

In developed countries, the epidemiology of bacterial meningitis in infants and children is undergoing a deep change. One of the reason is the generalization of the vaccination against the main germs [5]. On the other hand, Streptococcus pneumoniae with decreased sensibility in penicillin appeared and none vaccinal serotypes emerged [6] [7]. In Congo, according to a study published in 1998 [8], the lethality of bacterial meningitis of infants and children was to $43.4 \%$, and the most found germs were the Streptococcus pneumoniae (36.9\%) and Haemophilus influenzae b (2.9\%). Since then, Haemophilus influenzae b (Hib) vaccine in January, 2009, and Pneumococcal vaccine in October, 2012 were introduced in the national Expanded Program of Immunization. Thus, assuming that the introduction of Hib and Pneumococcal vaccines had resulted in the reduction of the incidence and the mortality of bacterial meningitis of infants and children, this study was initiated with the aim of determining the frequency, the epidemiological characteristics and outcomes of bacterial meningitis in infants and children at the Teaching Hospital of Brazzaville.

\section{Patients and Methods}

In this retrospective and descriptive study carried out between January 2004 and December, 2013 (10 years), in the Paediatric Intensive Care Unit (ICU) of the Teaching Hospital of Brazzaville. Children aged 1 to 59 months, whose discharged diagnosis bore the item confirmed or probable bacterial meningitis were included, with the exception of lymphocytic meningitis. The diagnosis of bacterial meningitis was considered as "confirmed" when the coloring of Gram and/or culture of the CSF was positive, and "probable" when the CSF analysis had at least one of the following characteristics: turbid appearance; leukocytosis $\left(>100\right.$ cells $\left./ \mathrm{mm}^{3}\right)$, or leukocytosis $\left(10-100\right.$ cells $\left./ \mathrm{mm}^{3}\right)$ and either an elevated protein $(>100 \mathrm{mg} / \mathrm{dl})$ or decreased glucose [9]. The global immunization status was considered as complete when the child received at least three doses of pneumococcal and Hib vaccines, and incomplete when the child received at maximum two doses. The unvaccinated child was the one who received no single dose of these two vaccines. The bacterial meningitis was considered as severe when one of the following symptoms was present: minor conscious disturbances, a focused neurological deficit, convulsions, neurovegetative disorders, an extensive purpura, a state of shock. When there was no possibility of doing CSF and/or blood cultures (due to technical platform issues), germs were identified according to their morphology: dip- 
lococci with positive Gram, lanceolate or spherical were considered as Streptococcus pneumoniae, and the small bacilli with negative gram, fine motionless as Hemophilus influenzae. According to the moment of introduction of both vaccines in the vaccination schedule of children aged 0 to 11 months, we defined the following periods: first before Hib vaccine from January, 2004 to December, 2008, and after Hib vaccine from January, 2009 to December, 2013, second before pneumococcal vaccine from January, 2004 to September, 2012, and after pneumococcal vaccine from October, 2012 to December, 2013.

Based on these criteria, the item bacterial meningitis was found as diagnosis at the time of discharge on 255 files, of which 219 were included in this study.

Analyzed variables were: age, gender, place of residence, the immunization status, place of origin, the consultation and hospitalization time limit, the cause for hospitalization, the CSF analysis results, the duration of hospitalization and the outcomes.

The data processing and analysis were done using the SPSS software (version 18, CHICAGO). The statistical tests used were Chi ${ }^{2}$ 's and Student's tests; a p-value below 0.05 was regarded as statistically significant.

\section{Results}

\subsection{Frequency, Sociodemographic Characteristics, Immunization Status, Clinical Aspects and Laboratory Findings}

During the study period, 22,148 children were hospitalized among which 11,074 were under five years old, and 219 had bacterial meningitis, among which 116 males (53.0\%) and 103 females (47.0\%), the male to female ratio of 1.1. The mean age was $21.8 \pm 19.5$ months, extreme ( 2 and 59 months). These children were aged one to 11 months in 101 cases (46.1\%) with 52 (23.7\%) aged under three months and 49 (22.4\%) four to 11 months; 12 to 23 months in 32 cases (14.6\%), 24 to 35 months in 21 cases (9.6\%), 36 to 47 months in 20 cases (9.2\%), and 48 months and above in 45 cases (20.5\%).

The hospital based frequency was $9.8 \%$. Table 1 shows the number of bacterial meningitis of infants and children and the total number of hospitalized patients per year.

They lived in Brazzaville, $\mathrm{n}=215$ (79.1\%) and four children (1.9\%) where from other regions of Congo.

Among the 219 cases, as regards the Hib vaccine, 144 children (65.8\%) were not vaccinated, and 63 of them were admitted after the introduction of the vaccine. The immunization status was incomplete for 15 children (6.8\%), and 60 (27.4\%) were correctly vaccinated.

Concerning the pneumococcal vaccine, 213 children (97.3\%) were not vaccinated. The six admitted children after the introduction of the pneumococcal vaccine had an incomplete vaccination status (three cases), and complete three cases as well (1.4\%).

The mean time between the onset of symptoms and the consultation was 3.08 
days extremes ( 1 - 13 days), and the average time limit between the beginning of the symptoms and the hospitalization was 5.86 days extremes ( $1-28$ days).

Symptoms that justified the consultation, isolated and/or associated were: fever $\mathrm{n}=214(9.7 \%)$, convulsions $\mathrm{n}=165(75.3 \%)$, vomiting $\mathrm{n}=76(34.7 \%)$, diarrhea $n=45(20.5 \%)$, headache $n=31(14.2 \%)$, constant crying $n=28(12.8 \%)$, flu episode $n=24(11.0 \%)$, hypotonia $n=11(5.0 \%)$, consciousness disorder $n=$ $11(5.0 \%)$, a respiratory distress $n=8(3.5 \%)$, an agitation $n=5(2.3 \%)$, shivers $n$ $=3(1.4 \%)$, a refusal to eat $\mathrm{n}=12(5.5 \%)$, a moaning $\mathrm{n}=1(0.1 \%)$.

Physical examination noted: coma $\mathrm{n}=133(60.7 \%)$, stiffness of the neck $\mathrm{n}=$ 37 (16.9\%), a motor deficit $n=2(0.9 \%)$.

Among the 219 cases of bacterial meningitis, 136 cases (62.1\%) were severe. The clinical elements of severity were: a coma (133 cases: $60.7 \%)$, a state of shock (13 cases: $5.9 \%$ ), a motor deficit (two cases: $0.9 \%$ ).

The frequency of meningitis based on children's age, the severity, and according to the period of the introduction of both vaccines is recorded in Table 1.

There was no statistically significant difference as regards the frequency of bacterial meningitis, the age of the onset and the severity of the disease according to the period of the introduction of both vaccines.

\subsection{Cerebrospinal Fluid Analysis}

The lumbar puncture done in all cases found a turbid fluid $\mathrm{n}=199$ (90.9\%), with pus $\mathrm{n}=15(6.8 \%)$ and xanthochromic $\mathrm{n}=5(2.3 \%)$.

Gram staining was performed in 112 children (51.2\%). In 46 cases (41.0\%), it showed Gram-positive Cocci in diplo and long chains attributed to Streptococcus pneumoniae, in 16 cases (14.3\%) with short and polymorphic gram-negative bacilli, corresponding to Haemophilus influenzae b, in 6 cases (5.4\%) isolated and in clusters Gram-positive Cocci linked to Staphylococcus aureus after culture, in 6 cases (5.4\%) Gram-negative bacilli attributed to Eschéricha Coli, and in 38 cases (33.9\%) the culture was sterile.

The search for the soluble antigens performed in 7 patients found Streptococcus

Table 1. Frequency of the meningitis according to the age, the severity and the period of the introduction of haemophilus inflenzae and pneumococcal vaccines.

\begin{tabular}{ccccc}
\hline & $\begin{array}{c}\text { Total } \\
\text { Hospitalized }\end{array}$ & $\begin{array}{c}\text { Meningitis } \\
\text { Bacterial }\end{array}$ & Age (month) & $\begin{array}{c}\text { Severe } \\
\text { Forms }\end{array}$ \\
\cline { 3 - 5 } & & $\mathrm{n}(\%)$ & Moyenne \pm écart type & $\mathrm{n}(\%)$ \\
\hline Before Hib & 4214 & $81(1.9)$ & $21.3 \pm 21.3$ & $46(56.8)$ \\
After Hib & 6860 & $138(2.0)$ & $22.1 \pm 16.4$ & $90(65.2)$ \\
Before Pneumo & 8847 & $183(2.0)$ & $21.6 \pm 19.8$ & $115(62.8)$ \\
After Pneumo & 2227 & $36(1.6)$ & $23.8 \pm 18.2$ & $21(58.3)$ \\
Total & 11,074 & $219(1.9)$ & $21.8 \pm 19.5$ & $136(62.1)$ \\
\hline
\end{tabular}

$p=0.86$ for the Haemophilus vaccine $b, p=0.52$ for the pneumococcal vaccine. 
pneumoniae (3 cases), Haemophilus influenzae (3 cases), and the germ was not identified in one case.

\subsection{Treatment}

After the lumber puncture was done, an empiric antibiotic therapy was administered to every child. For infants below three months of age, three antibiotics including a third generation cephalosporin, amoxicillin and aminoglycoside were administered in 19 cases (8.7\%). For those aged three months and above, a single antibiotic, which was a third generation cephalosporin, was administered in all cases. Thiamphenicol or ciprofloxacin were added in 14 (6.4\%) and two cases $(0.9 \%)$ respectively.

\subsection{Outcomes}

The mean duration of hospitalization was $9.1 \pm 6.2$ days extremes ( 1 and 26 days). Healing was obtained in 124 cases, without sequelae in 121 cases (55.2\%), with sequelae in 3 cases (1.4\%) represented by hydrocephalus: two cases, and epilepsy: one case. In 95 cases 43.4\%, the course led to a death (Table 2 and Figure 1).

\section{Discussion}

This study which aim was to determine the frequency, the epidemiological cha-

Table 2. Lethality, and mortality according to vaccinal period.

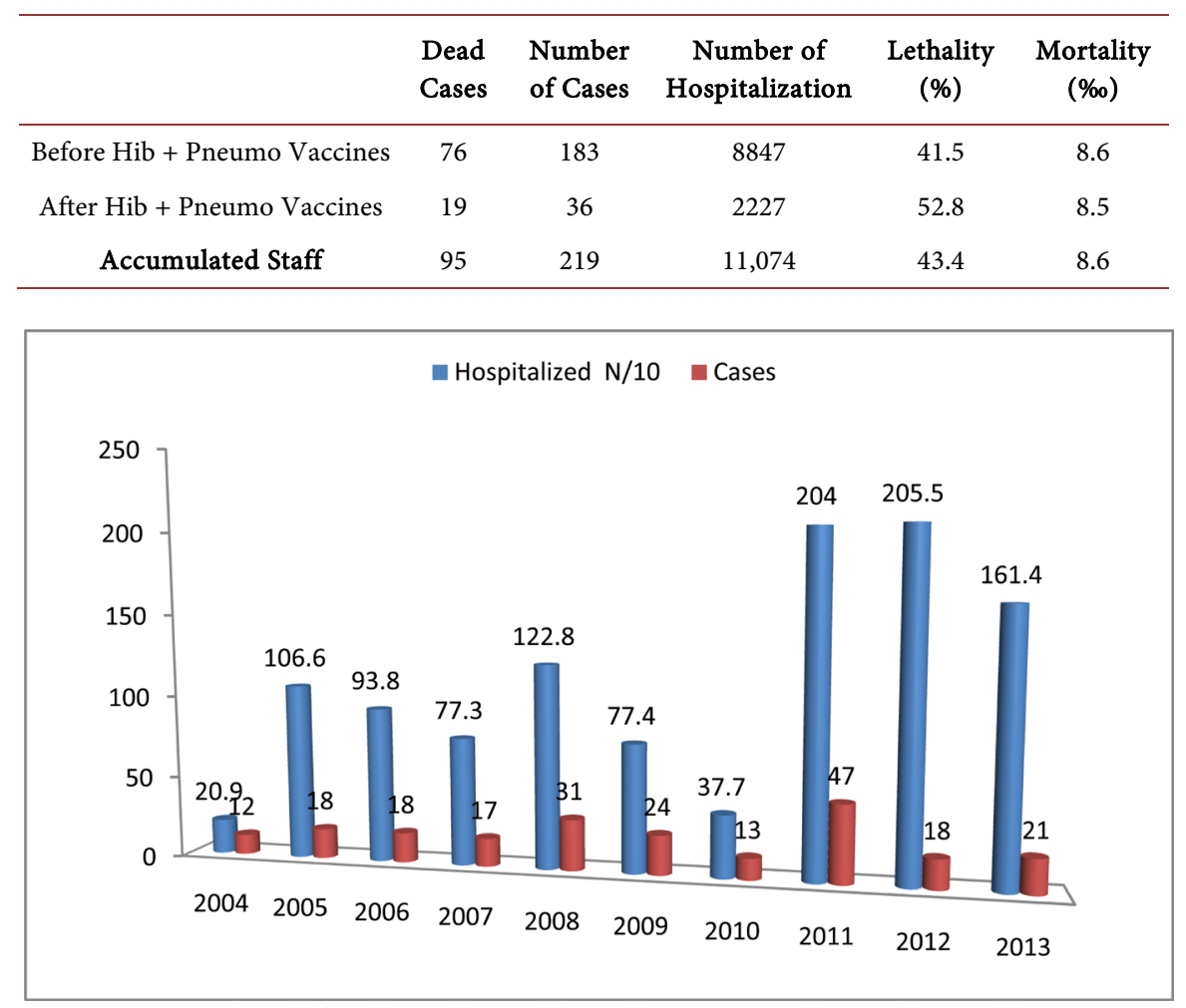

Figure 1. Number of cases of bacterial meningitis per year. 
racteristics and outcomes of bacterial meningitis of infants and children in Brazzaville after the introduction of pneumococcal and Hib vaccines. It showed that the frequency of bacterial meningitis is still high independently to period considered (before and after the introduction of the above vaccines). The most affected children had a mean age of $21.8 \pm 19.5$ months, insufficiently or not vaccinated. The main found germs are: Streptococcus pneumoniae and Hemophilus influenzae. The high mortality testifies the severity of the disease.

This study has probably some limitations. First it is a retrospective study; the constitution of the sample justifies some biases. We reviewed medical records of hospitalized children over a ten-year time period. Under these conditions, it is possible that many records were not taken into account because, either they were lost or could not be used, or not including some relevant data. The second bias relates to the technical platform of the laboratory which is deficient, as evidenced by the low number of isolated germs and blood cultures performed, plus the possible confusion in the identification of germs.

However, this study has some strengths. First, the choice of the study duration, with the need of obtaining a representative sample. In fact, 10 years seemed to be for us an acceptable period of time during which we could assess the frequency of bacterial meningitis after the introduction of pneumococcal and Hib vaccines. Second, the choice of the age group from two months to five years was guided by the fact that the lower limit (two months) corresponds to the administration of the first dose of both vaccines. Further, the upper limit of this range (five years) is the moment when the first group of children who received the Hib vaccine (introduced in 2009) was 5-year-old (December, 2013).

Last, although the study was conducted in one center, but this one is largest and the only existing department providing cares to seriously ill children in the city.

\subsection{Frequency}

The frequency of bacterial meningitis was $0.99 \%$, showing that this remains a health problem in Congo. When we consider the vaccinal periods, before the introduction of both vaccines, 81 cases of bacterial meningitis were reported among 4214 hospitalized children, thus a frequency of $1.9 \%$. This frequency is close to that reported by Moyen et al. [8] in a study carried out in the same department on children aged one month to 15 years old. After the introduction of vaccines, 102 cases $(2.2 \%)$ of bacterial meningitis were noted among 4633 hospitalized children, higher than the one in the study of Moyen [8]. This finding is contrary to data from the literature [10] [11], that report a significant decrease of the frequency of meningitis, especially after the introduction of the Hib vaccine. Susana Scott et al. reported an annual reduction in bacterial meningitis from 52 cases/100.000 inhabitants to 43/100.000 [10]. Similarly, Luciana Leite Pineli Simoes et al. in Brazil noted a reduction of cases of probable bacterial meningitis of 39\%, then $53 \%$ respectively during the first and the second year of the Hib vaccination 
[11].

But, the difference between the results of this study and those of consulted authors is that despite the introduction and the free access of vaccines, 144 children (65.8\%) were not vaccinated against haemophilus and 63 were admitted after the introduction of this vaccine. Likewise, the vaccination status was incomplete in 15 children (6.8\%), and only 60 children (27.4\%) were correctly vaccinated. concerning the pneumococcal vaccine, 213 children $(97.3 \%)$ were not vaccinated, and six of them admitted after the introduction of the vaccine had an incomplete vaccination status ( 3 cases, 1.4\%) and up-to-date ( 3 cases, 1.4\%). These results raise the issue of the populations' adherence to the health system and therefore that of the vaccination coverage.

\subsection{Age, Gender, and Origin}

The mean age was 21.82 months \pm 19.55 months, the most affected group age was the one from 2 to 11 months (46.1\%). The same notice was made by several authors: Abdou H. et al. [12], and Kone O. et al. in Bamako [13] who respectively reported frequencies of $56.4 \%$ and $42.8 \%$ among infants aged one to 11 months old. There is no influence of gender in the onset of bacterial meningitis as noted previously [8] [13] [14]. Children were from Brazzaville in 97\% of cases, mainly from high density populated districts (46.3\%). The same notice was made by Moyen et al. [8] in the same department, and Camara B. et al. in Senegal [14].

\subsection{Germs}

The obsolete nature of the technical platform of the laboratory in our facility leads us, like others [15], to use operational definitions such as confirmed or probable meningitis. In addition there are a significant number of unidentified germs.

The most found germs (Streptococcus pneumoniae and the Haemophilus influenzae b), being germs against which vaccines are available and accessible at all levels, compels the need to strengthen education and communication for a better appropriation by the population. Indeed, the benefits of the Hib vaccine on the onset the meningitis are well-documented [10] [11] [15], as well as the role in the prevention of invasive infections of the pneumococcal vaccine. Therefore, the generalization of these vaccines accounts in the fact that the epidemiology of meningitis in developed countries is different from that of developing countries, especially in Africa. In developed countries, meningitis due to Haemophilus influenzae are currently exceptional [10] [11] [16], and more and more they are referring to pneumococcus with a sensibility diminished to penicillin [17]. For other authors, vaccination had increased the frequency of multiresistant and non-vaccinal serotypes, as postulated by Pelton et al. [17] who noted the emergence of non-vaccinal 19A serotype in Massachusetts after the introduction of the pneumococcal conjugated vaccine (PCV). Gonzalez et al. noted the emergence of 15 and 33 serotypes after the introduction of the PCV7 in the United States [6]. In Africa, where meningitis is still frequent, the generalization of these vaccines is imperative with a 
definite interval assessment.

\subsection{Outcomes}

Bacterial meningitis of infants and the children remain severe as demonstrated by the high rate of mortality in Africa [8] [13]. In this study, the mortality of children aged from 2 to 59 months before the introduction of the Hib vaccine was 7.1 for 1000 hospitalizations, compared to 8.5 for 1.000 hospitalizations after its introduction. The lethality was $37 \%$ before the introduction of both vaccines; then, it rose to $528 \%$ after their introduction. These frequencies are similar to those noted by Moyen et al. [8]. But, if the place of the vaccination in the reduction of morbidity due to meningitis is well known, other determinants of morbidity and mortality need to be identified for a better prevention against bacterial meningitis.

\section{Conclusion}

Bacterial meningitis remains frequent among infants and children aged from two to 59 months in Brazzaville. Infants aged 2 to 11 months, who are not or insufficiently vaccinated (which testifies the low population adherence to the national expanded program on immunization), are the most affected. The main germs are: Streptococcus pneumoniae and Haemophilus influenzae $b$. The mortality is still high.

\section{References}

[1] Kim, K.S. (2010) Acute Bacterial Meningitis in Infants and Children. The Lancet Infectious Diseases, 10, 32-42. https://doi.org/10.1016/S1473-3099(09)70306-8

[2] Owusu, M., Nguah, S.B., Boaitey, Y.A., Badu-Boateng, E., Abubakr, A.-R., Lartey, R.A. and Adu-Sarkodie, Y. (2012) Aetiological Agents of Cerebrospinal Meningitis: A Retrospective Study from a Teaching Hospital in Ghana. Annals of Clinical Microbiology and Antimicrobials, 11, 28. https://doi.org/10.1186/1476-0711-11-28

[3] Shrestha, R.G., Tandukar, S., Ansari, S., Subedi, A., Shrestha, A., Poudel, R., Adhikari, N., Basnyat, S.R. and Sherchand, J.B. (2015) Bacterial Meningitis in Children under 15 Years of Age in Nepal. BMC Pediatric, 15, 94. https://doi.org/10.1186/s12887-015-0416-6

[4] Obermaier, B., Klein, M., Koedel, U. and Pfister, H.-W. (2006) Disease Models of Acute Bacterial Meningitis. Drug Discovery Today. Deases Models, 3, 105-112. https://doi.org/10.1016/j.ddmod.2006.03.010

[5] Levy, C., Varond, E., Taha, M.-K., Béchet, S., Bonacorsi, S., Cohen, R. and Bingen, E. (2014) Change in French Bacterial Meningitis in Children Resulting from Vaccination. Archives de Pédiatrie, 21, 736-744. https://doi.org/10.1016/j.arcped.2014.04.025

[6] Gonzalez, B.E., Hulten, K.G., Lamberth, L., Kaplan, S.L. and Mason Jr, E.O. (2006) Streptococcus Pneumonia Serogroups 15 and 33: An Increasing Cause of Pneumococcal Infections in Children in the United States after the Introduction of Pneumococcal 7-Conjugate Vaccine. The Pediatric Infectious Disease Journal, 25, 301-305 https://doi.org/10.1097/01.inf.0000207484.52850.38

[7] Auburtin, M. and Timsit, J.F. (2001) Pneumococcal Meningitis: Current Opinion and Future. Réanimation, 10, 291-301. 
https://doi.org/10.1016/S1164-6756(01)00117-7

[8] Moyen, G. and Mbika-Cardorelle, A. (1999) Bacterial Meningitis of Infants and Children at the Teaching Hospital of Brazzaville. Archives de Pédiatrie, 6, 108-109. https://doi.org/10.1016/S0929-693X(99)80088-8

[9] World Health Organization (2012) Measuring Impact of Streptococcus Pneumoniae and Haemophilus influenzae Type b Conjugate Vaccination. OMS, Geneva, 33, 55.

[10] Scott, S., Altanseseg, D., Sodbayer, D., Nymadawa, P., Bulgan, D., Mendsaikhan, J., et al. (2013) Impact of Haemophilus influenzae Type b Conjugate Vaccine in Mongolia: Prospective Population-Based Surveillance, 2002-2010. The Journal of Pediatrics, 163, S8-S11. https://doi.org/10.1016/j.jpeds.2013.03.024

[11] Simoes, L.L.P., Andrade, A.L.S.S., Laval, C.A., Oliveira, R.M., Silva, S.A., Martelli, C.M.T., de A. Alves, S.L., Almeida, R.M. and Andrade, J.G. (2004) Impact of Haemophilus Influenae b (Hib) Vaccination on Meningitis in Central Brazil. Revista de Saúde Pública, 5, 38.

[12] Abdou, H. (2000) Clinical, Bacteriological, Therapeutic and Progressive Aspects of Purulent Meningitis in Infants and Children in the Pediatric Department IV of Gabriel Touré Hospital. Master Thesis, $\mathrm{N}^{\circ} 52$, Bamako.

[13] Kone, O. (1999) Epidemioclinical Approach of Purulent Meningitis Observed in Pediatrics at Gabriel Touré Hospital in 1998. Master Thesis, $\mathrm{N}^{\circ} 43$, Bamako.

[14] Camara, B., Cissé, M.F., Faye, P.M., Ba, M., Tal-Dia, A., Diouf, S., Diagne, I., Gueye Diagne, N.R., Ba, A., Cissé Gueye, A., Sow, D. and Kuakuvi, N. (2003) Purulent Meningitis in a Pediatric Hospital in Dakar, Senegal. Médecine et Maladies Infectieuses, 33, 422-426. https://doi.org/10.1016/S0399-077X(03)00221-X

[15] Rafaravavy, N.E., Randrianjafinimpanana, H. and Robinson, A.L. (2014) Bacteriological Profile of Meningitis in Hospitalized Children in Tsaralalana Madagascar. Arch Pédiatr, 21, 802. https://doi.org/10.1016/S0929-693X(14)72062-7

[16] Levy, C., De la Roque, F. and Cohen, R. (2009) Update of the Epidemiology of Bacterial Meningitis in Children in France. Médecine et Maladies Infectieuses, 39, 419-431. https://doi.org/10.1016/j.medmal.2009.03.006

[17] Pelton, S.I., Huot, H., Finkelstein, J.A., et al. (2006) Emergence of 19A as Virulent and Multidrug Resistant Pneumococcus in Massachusetts Following Universal Immunization of Infants with Pneumococcal Conjugate Vaccine. The Pediatric Infectious Disease Journal, 25, 494-495. 